\title{
Radio-Frequency Interference Identification Over Oceans for C- and X-Band AMSR2 Channels
}

\author{
Zabolotskikh Elizaveta ${ }^{1}$, Mitnik Leonid M. ${ }^{2}$, Chapron Bertrand ${ }^{3}$ \\ ${ }^{1}$ Russian State Hydrometeorol Univ, Satellite Oceanog Lab, St Petersburg 195196, Russia. \\ ${ }^{2}$ Russian Acad Sci, VI llichev Pacific Oceanol Inst, Far Eastern Branch, Vladivostok 690041, Russia. \\ ${ }^{3}$ Inst Francais Rech Exploitat Mer, F-29280 Plouzane, France.
}

Corresponding authors : email addresses : liza@rshu.ru ; mitnik@poi.dvo.ru ; bchapron@ifremer.fr

\begin{abstract}
:
A new method for radio-frequency interference (RFI) contamination identification over open oceans for the two C-subbands and X-band of Advanced Microwave Scanning Radiometer 2 (AMSR2) channel measurements is suggested. The method is based both on the AMSR2 brightness temperature (T-B) modeling and on the analysis of AMSR2 measurements over oceans. The joint analysis of T-B spectral differences allowed to identify the relations between them and the limits of their variability, which are ensured by the changes in the environmental conditions. It was found that the constraints, based on the ratio of spectral differences, are more regionally and seasonally independent than the spectral differences themselves. Although not all possible RFI combinations are considered, the developed simple criteria can be used to detect most RFI-contaminated pixels over the World Ocean for AMSR2 measurements in two C-subbands and the X-band.
\end{abstract}

Keywords : Atmosphere, geophysical measurement techniques, oceans, passive microwave remote sensing, radio-frequency interference (RFI)

\section{Introduction}

$\mathrm{HE}$ problem of radio frequency interference (RFI) impact on geophysical parameter retrievals from satellite passive microwave radiometers (PMW) continues to get more and more serious during the last decades. Remote sensing observations experience RFI since they share the allocated bands with media broadcast communication satellites and many various ground RFI signal sources [1]. Observing more bandwidth tends to yield less noise, but also leads to more interference. RFI areas should be carefully identified to avoid spurious trends in climate data records. The special issue of IEEE Transactions on Geoscience and Remote Sensing provides an overview of the most recent studies in the field of RFI identification and mitigation [2] and currently known RFI sources [3]. These studies 
relate both to methodological issues, associated with RFI detection, and hardware developments to mitigate RFI signals [4]. Not only PMW measurements suffer from RFI. Synthetic aperture radar (SAR) data also need to be corrected for RFI [5]. RFI is comparatively small over the oceans [6]. The situation is much worse over land, so most RFI related studies refer to land applications [7].

While many techniques, including spectral difference or multichannel correlation analysis are developed to identify and flag the data affected by large RFI contamination [6], low level RFI contamination can be difficult to identify [8]. Moreover these techniques are supposed to be of no use over oceans where the natural variability of the spectral differences is comparable with low level RFI [6]. The spectral differences over the oceans are governed by highly variable sea surface wind speed and atmospheric parameters (water vapor, cloud liquid water and precipitation) ensuring much higher values of their natural variability than over the lands. Over the oceans the model difference technique can be used basing on the difference between measured and simulated brightness temperatures considered as RFI. For example in [6] such a technique is used to detect X-band RFI for Advanced Microwave Sounding Radiometer - Earth Observing System (AMSR-E) channels at $10.65 \mathrm{GHz}$ under rain free conditions. The new Japan radiometer AMSR2 was launched onboard GCOM-W1 satellite on 18 May 2012 and substituted Aqua AMSR-E. Almost 10 years of stable AMSR-E performance provided scientific community with well calibrated series of such geophysical products as sea surface temperature (SST), sea surface wind speed (SWS), atmospheric water vapor content (WVC), cloud liquid water content (CLW) and others. The lower frequency channels of AMSR2, particularly C- and X-band channels, similar to those of AMSR-E and WindSat radiometer, are mostly influenced by RFI since these bands are used extensively for media broadcasting. As such, all the geophysical parameters estimated from the measurements at these channels are false retrieved over RFI influenced areas. These are basically SST and SWS. Remote Sensing Systems detect regions of RFI by differencing AMSR-E SSTs derived using all microwave channels from those SSTs derived 
without using the $6.9 \mathrm{GHz}$ channel [9]. But this difference method can be used for strong RFI sources only, since low level RFI influence on SST is comparable with the second (without using the $6.9 \mathrm{GHz}$ channel) algorithm retrieval errors.

Large RFI induced errors in the AMSR-E ocean products were thoroughly investigated during the entire mission. The effects of different RFI sources were studied for the whole time period of interference [1]. At that the sources of RFI and use of more frequencies near PMW instrument measurement bandwidths, continue to increase. This is mostly relative to low power unregulated sources [3] with large time and spatial variability.

Specifically to distinguish low level RFI - contaminated footprints new dual-polarization channels in $7.3 \mathrm{GHz}$ band were added to AMSR2. Measurements at close frequencies are featured by similar dependencies on the atmospheric and oceanic parameters and highly correlate over RFI-free areas under various environmental conditions. The presence of even low level RFI at one of the channels decorrelates channel measurements affecting the spectral difference. Different response to RFI at 6.9 and $7.3 \mathrm{GHz}$ bands allows discriminating RFI influenced areas for $6.9 \mathrm{GHz}$ channel measurements using just a simple threshold technique applied to the difference between the measurements at 7.3 and 6.9 $\mathrm{GHz}$ on the same polarization [10].

Beside a simple spectral difference method to identify RFI at $6.9 \mathrm{GHz}$ [10], a model-based approach, developed for WindSat [6] can also be used for RFI at $10.65 \mathrm{GHz}$ detection in AMSR2 measurement data. This method requires prior identification of rain scenes to be removed, thus being limited to precipitation free areas. The difference method of [9] to detect RFI at $6.9 \mathrm{GHz}$ in AMSR-E data can also be applied but it is inefficient in low-level RFI identification.

In this study we suggest a new method for RFI identification over open oceans for all 6 AMSR2 C- and Xband channels. The method is based both on AMSR2 brightness temperature $\left(T_{B}\right)$ modeling and on the analysis of empirical AMSR2 data over oceans. The general basis of the method is the strong correlation between AMSR2 channel difference measurements in the absence of RFI. Joint analysis of $T_{B}$ spectral differences allows to identify the relations between them and the limits of their variability, ensured by the changes in the environmental conditions. These limits were derived for RFI detection at the 6.9, 7.3 and $10.65 \mathrm{GHz}$ channels at both polarization states. Since $T_{B}$ model for AMSR2 radiance calculations is valid only for nonprecipitating conditions we extended the analysis including empirical AMSR2 measurement data to account for precipitation and shifted the RFI threshold values accordingly.

\section{APPROACH}

The method to identify RFI areas is based on the results of the numerical modeling of the atmosphere - ocean system brightness temperatures under non-precipitating conditions accompanied by the analysis of AMSR2 measured $T_{B}$ fields. $\mathrm{T}_{\mathrm{B}}$ simulation was done using the geophysical model described in [11]. This model and the dataset for numerical simulations were already successfully used for the development of the algorithms for SST, SWS, WVC, CLW and total atmospheric absorption retrievals from GCOM-W1 AMSR2 measurements [12].

After model simulations, we identified the discriminative functions, for which simple threshold values could be used to distinguish the physical range of values from "non-physical" range, ensured by RFI. The reasons for the selection of such variables are the following:

1) The natural differences in measurements at microwave frequencies in C- and X-band are due to the atmospheric and oceanic parameter variations. Consequently, when ensured by environmental changes they should strongly correlate to each other contrarily to signals from external sources of microwave radiation;

2) Brightness temperature difference at close frequency channels at a single polarization over the oceans is mainly a function of the atmospheric water variables (WVC, CLW and precipitation) [13], being more independent on the sea state changes [14] and thus, more appropriate for defining the RFI criteria (less sensitive to sea surface wind variations).

Thus, for the simulated dataset of brightness temperatures we investigated the following spectral differences in measurements and their relations in $\mathrm{C}$ - and $\mathrm{X}$-band, taken at the same polarization state: $\mathrm{DT}_{\mathrm{X}, \mathrm{C} 1}{ }^{\mathrm{H}}$ as a function of $\mathrm{DT}_{\mathrm{C} 2, \mathrm{C} 1}{ }^{\mathrm{H}}$, $\mathrm{DT}_{\mathrm{X}, \mathrm{C} 1}{ }^{\mathrm{H}}$ as a function of $\mathrm{DT}_{\mathrm{X}, \mathrm{C} 2}{ }^{\mathrm{H}}$ and $\mathrm{DT}_{\mathrm{X}, \mathrm{C} 1}{ }^{\mathrm{H}} / \mathrm{DT}_{\mathrm{C} 2, \mathrm{C} 1}{ }^{\mathrm{H}} / \mathrm{T}_{\mathrm{C} 1}{ }^{\mathrm{H}}$ as a function of $\mathrm{DT}_{\mathrm{C} 2, \mathrm{C} 1}{ }^{\mathrm{H}}$. Instead of the last ratio $\mathrm{DT}_{\mathrm{X}, \mathrm{C} 2}{ }^{\mathrm{H}} / \mathrm{DT}_{\mathrm{C} 2, \mathrm{C} 1}{ }^{\mathrm{H}} / \mathrm{T}_{\mathrm{C} 2}{ }^{\mathrm{H}}$ can be used. Here $\mathrm{DT}_{\mathrm{X}, \mathrm{C} 1}{ }^{\mathrm{H}}=\mathrm{T}_{10.65}{ }^{\mathrm{H}}-$ $\mathrm{T}_{6.9}{ }^{\mathrm{H}} ; \mathrm{DT}_{\mathrm{C} 2, \mathrm{C} 1}{ }^{\mathrm{H}}=\mathrm{T}_{7.3}{ }^{\mathrm{H}}-\mathrm{T}_{6.9}{ }^{\mathrm{H}} ; \mathrm{DT}_{\mathrm{X}, \mathrm{C} 2}{ }^{\mathrm{H}}=\mathrm{T}_{10.65}{ }^{\mathrm{H}}-\mathrm{T}_{7.3}{ }^{\mathrm{H}} ; \mathrm{T}_{\mathrm{C} 1}{ }^{\mathrm{H}}=$ $\mathrm{T}_{6.9}{ }^{\mathrm{H}}$, where $\mathrm{T}_{6.9}{ }^{\mathrm{H}}, \mathrm{T}_{7.3}{ }^{\mathrm{H}}, \mathrm{T}_{10.65}{ }^{\mathrm{H}}$ - the brightness temperatures measured at 6.9, 7.3 and $10.65 \mathrm{GHz}$, horizontal polarization, correspondingly. The same spectral differences were analyzed for vertically polarized measurements.

The relations between modeled spectral differences in Cand X-band channels at horizontal polarization are presented in Fig. 1(a). The lower picture shows some function of spectral differences and $\mathrm{T}_{6.9}{ }^{\mathrm{H}}$, which will be used for identification of RFI at $10.65 \mathrm{GHz}$. Then, since the model calculations are restricted by non-precipitating conditions, we analyzed suggested discriminative functions, derived empirically from AMSR2 Level 1B brightness temperature data. The data sample was created from the measurements taken far from land or other known RFI sources (e.g. reflected signals from geostationary satellites) for precipitating and nonprecipitating conditions for the whole range of environmental conditions. Similar approach to analyze the relationships among the channels of the Special Sensor Microwave/Imager was successfully used in the past in developing a decision tree algorithm to identify snow cover and precipitation over land and ocean [15]. Fig. 1(b) shows the same spectral differences and their functions as Fig. 1(a) but for actual AMSR2 Level $1 \mathrm{~B}$ brightness temperature data, including precipitating areas. The plots in Fig. 1(b) are built from the AMSR2 measurements far from land RFI sources or other possible known RFI sources.

Analyzing the values of $\mathrm{DT}_{\mathrm{C} 2, \mathrm{C} 1}{ }^{\mathrm{H}, \mathrm{V}}, \mathrm{DT}_{\mathrm{X}, \mathrm{Cl}}{ }^{\mathrm{H}, \mathrm{V}}, \mathrm{DT}_{\mathrm{X}, \mathrm{C} 2}{ }^{\mathrm{H}, \mathrm{V}}$ and their relations we found the limits of their variability 
ensured by the atmospheric and oceanic parameter variability. When these relations fell out of the limits, derived from such an analysis, we had the case of RFI. To illustrate how the formulated constrains help to identify RFI pixels we analyzed AMSR2 data for various seasons and geographical regions. Some of the illustrative examples are given in the Auxiliary materials. Each of the examples shows also how the dependencies, presented in Fig. 1, are changed by the respective RFI.
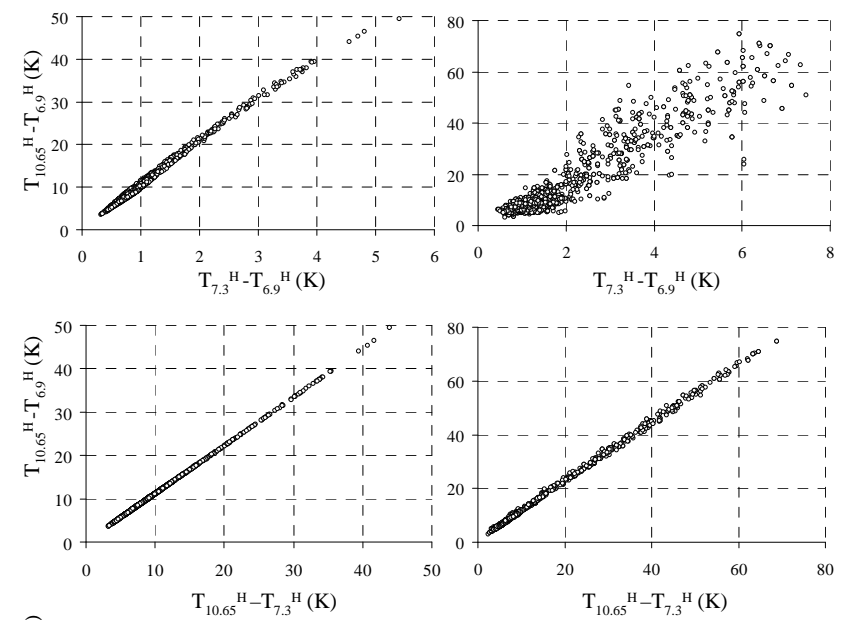

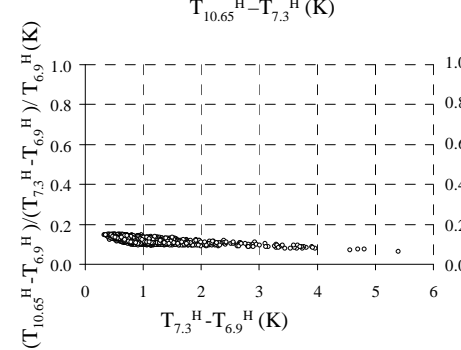

(a)

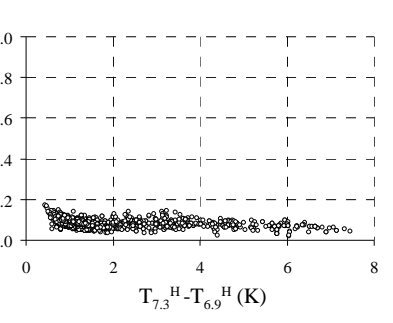

(b)
Fig. 1. Spectral difference functions of AMSR2 measurements at horizontal polarization at C- and X-band channels for natural atmospheric and oceanic parameter variations: (a) model calculations without precipitation; (b) AMSR2 measurements over the oceans, including precipitating areas.

\section{RESULTS}

Below we formulate the results of the analysis of the spectral differences and their interrelations at AMSR2 C- an $\mathrm{X}$-band channel measurements relatively to each of the considered RFI contamination types. The summary of the results is generalized in the form of the decision tree aiming to help in RFI identification (Fig. 2).

\section{A. RFI at $6.9 \mathrm{GHz}$}

Model calculations show that $\mathrm{DT}_{\mathrm{C} 2 \mathrm{C} 1}=\mathrm{T}_{7.3}-\mathrm{T}_{6.9}$ cannot be lower than $\sim 0.3 \mathrm{~K}$ for both polarization states. According to AMSR2 measurement data analysis $\mathrm{DT}_{\mathrm{C} 2, \mathrm{C1}}{ }^{\mathrm{H}} \min =0.5 \mathrm{~K}$, $\mathrm{DT}_{\mathrm{C} 2, \mathrm{C} 1} \mathrm{~V}_{\min }=0.4 \mathrm{~K}$.

Setting hereafter the thresholds for minimum spectral differences we present the results of model calculations. If $\mathrm{DT}_{\mathrm{C} 2, \mathrm{Cl}}{ }^{\mathrm{H}, \mathrm{V}}<0.3 \mathrm{~K}$ we have the case of RFI at $6.9 \mathrm{GHz}\left(\mathrm{RFI}_{6.9}\right)$ for horizontal $(\mathrm{H})$ or vertical $(\mathrm{V})$ polarization. At this, if there is RFI at $7.3 \mathrm{GHz}\left(\mathrm{RFI}_{7.3}\right)$ also, the formulated rule does not work. In such a case the value of $\mathrm{DT}_{\mathrm{X}, \mathrm{C} 1}=\mathrm{T}_{10.65}-\mathrm{T}_{6.9}$ can be used, if there is no simultaneous RFI at $10.65 \mathrm{GHz}$.

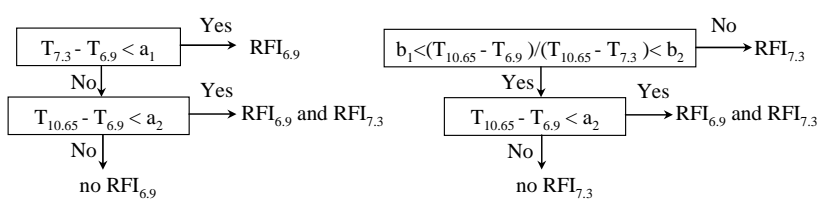

(a)

(b)

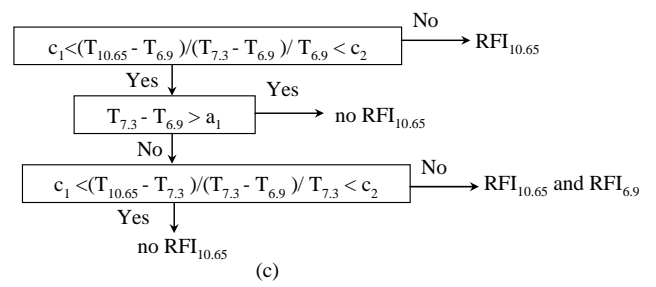

Fig. 2. Decision tree for identification RFI contaminated pixels: (a) at 6.9 $\mathrm{GHz}$; (b) at $7.3 \mathrm{GHz}$; (c) at $10.65 \mathrm{GHz}$. For horizontally polarized radiation $\mathrm{a}_{1}=0.3 \mathrm{~K}, \mathrm{a}_{2}=3.3 \mathrm{~K}, \mathrm{~b}_{1}=1.07, \mathrm{~b}_{2}=1.4, \mathrm{c}_{1}=0.03 \mathrm{~K}^{-1}, \mathrm{c}_{2}=0.15 \mathrm{~K}^{-1}$. For vertically polarized radiation $\mathrm{a}_{1}=0.3 \mathrm{~K}, \mathrm{a}_{2}=3.6 \mathrm{~K}, \mathrm{~b}_{1}=1.04, \mathrm{~b}_{2}=1.1, \mathrm{c}_{1}=0.03 \mathrm{~K}^{-1}, \mathrm{c}_{2}=0.15 \mathrm{~K}^{-1}$.
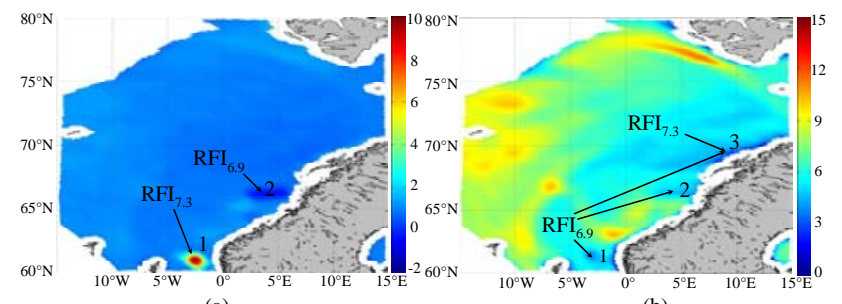

(a)

(b)

Fig. 3. AMSR2 spectral differences on 1 January 2012 at 11:18 UTC: (a) $\mathrm{T}_{7.3}{ }^{\mathrm{H}}-\mathrm{T}_{6.9}{ }^{\mathrm{H}}(\mathrm{K})$; (b) $\mathrm{T}_{10.65}{ }^{\mathrm{H}}-\mathrm{T}_{6.9}{ }^{\mathrm{H}}(\mathrm{K})$.

According to numerical modeling results $\mathrm{DT}_{\mathrm{X}, \mathrm{Cl}}{ }^{\mathrm{H}} \min =$ 3.3K, $\mathrm{DT}_{\mathrm{X}, \mathrm{C} 1} \mathrm{v}_{\min }=3.6 \mathrm{~K}$. So if we define the criteria for 6.9 GHz RFI as: $\mathrm{DT}_{\mathrm{C} 2, \mathrm{C} 1}{ }^{\mathrm{H}, \mathrm{V}}<0.3 \mathrm{~K}$ or $\mathrm{DT}_{\mathrm{X}, \mathrm{C} 1}{ }^{\mathrm{H}}<3.3 \mathrm{~K}\left(\mathrm{DT}_{\mathrm{X}, \mathrm{C} 1}{ }^{\mathrm{V}}<\right.$ 3.6K) we detect all RFI areas at $6.9 \mathrm{GHz}$, excluding the cases with RFI at all three frequencies. If $\mathrm{DT}_{\mathrm{C} 2, \mathrm{C} 1}^{\mathrm{H}, \mathrm{V}}>0.3 \mathrm{~K}$ and $\mathrm{DT}_{\mathrm{X}, \mathrm{C} 1}{ }^{\mathrm{H}}<3.3 \mathrm{~K}\left(\mathrm{DT}_{\mathrm{X}, \mathrm{C} 1}^{\mathrm{V}}<3.6 \mathrm{~K}\right)$ we have RFI at 6.9 and 7.3 $\mathrm{GHz}$ simultaneously. The decision tree to outline the steps for $\mathrm{RFI}_{6.9}$ identification is presented in Fig. 2(a). The regional values of minimum spectral differences to identify more RFI contaminated pixels can be somewhat larger due to different atmospheric and oceanic background.

This type of RFI can be visually detected by side by side analysis of $\mathrm{DT}_{\mathrm{C} 2, \mathrm{C} 1}$ and $\mathrm{DT}_{\mathrm{X}, \mathrm{C} 1}$. Easily detectable $\mathrm{RFI}_{6.9}$ in area 2 manifests itself as a dark blue area $\left(\mathrm{DT}_{\mathrm{C} 2, \mathrm{Cl}}{ }^{\mathrm{H}, \mathrm{V}}<0.3 \mathrm{~K}\right)$ in the field of $\mathrm{DT}_{\mathrm{C} 2, \mathrm{C} 1}$ (Fig. 3(a)). Area 1 can also be referred as $\mathrm{RFI}_{6.9}$, by the criterion $\mathrm{DT}_{\mathrm{X}, \mathrm{C} 1}{ }^{\mathrm{H}}<3.3 \mathrm{~K}$ (blue colored pixels in Fig. 3 (b)), but it cannot be visually identified in $\mathrm{DT}_{\mathrm{C} 2, \mathrm{C} 1}{ }^{\mathrm{H}, \mathrm{V}}$ field due to strong RFI at $7.3 \mathrm{GHz}$. Area 3 presents the case of simultaneous RFI of almost equal intensity in both $\mathrm{C}$ subbands. It cannot be identified in Fig. 3 (a), but it is well detected in $\mathrm{DT}_{\mathrm{X}, \mathrm{C} 1}{ }^{\mathrm{H}}$ field in Fig. 3 (b).

\section{B. RFI at $7.3 \mathrm{GHz}$}

An excess in the spectral difference $\mathrm{DT}_{\mathrm{C} 2, \mathrm{C} 1}{ }^{\mathrm{H}, \mathrm{V}}$ above some background can indicate both $\mathrm{RFI}_{7.3}$ and the presence of liquid precipitation. In case of $\mathrm{RFI}_{7.3}$ the ratio of $\mathrm{DT}_{\mathrm{X}, \mathrm{Cl}} \mathrm{H}, \mathrm{V}$ to $\mathrm{DT}_{\mathrm{X}, \mathrm{C} 2} \mathrm{H}, \mathrm{V}$ can be used for $\mathrm{RFI}_{7.3}$ detection. Middle plots in Fig. 1 show that this ratio should fall into some range of values defined by the natural variability of the atmospheric 
conditions. Under clear sky conditions it is close to one, whereas liquid water emission moves the ratio to higher values. For the ocean areas, not contaminated by $\mathrm{RFI}_{7.3}$, $\mathrm{DT}_{\mathrm{X}, \mathrm{C} 1}{ }^{\mathrm{H}} / \mathrm{DT}_{\mathrm{X}, \mathrm{C} 2}^{\mathrm{H}} \sim 1.07 \div 1.4, \mathrm{DT}_{\mathrm{X}, \mathrm{C} 1} \mathrm{~V}^{\mathrm{V}} / \mathrm{DT}_{\mathrm{X}, \mathrm{C} 2} \sim 1.04 \div 1.1$. If $\mathrm{DT}_{\mathrm{X}, \mathrm{C} 1}^{\mathrm{H}} / \mathrm{DT}_{\mathrm{X}, \mathrm{C} 2}^{\mathrm{H}}>1.4$ or $\mathrm{DT}_{\mathrm{X}, \mathrm{C} 1}{ }^{\mathrm{H}} / \mathrm{DT}_{\mathrm{X}, \mathrm{C} 2}{ }^{\mathrm{H}}<1.07$ (intense $\left.\mathrm{RFI}_{7.3}{ }^{\mathrm{H}}\right), \mathrm{RFI}_{7.3}{ }^{\mathrm{H}}$ is present; If $\mathrm{DT}_{\mathrm{X}, \mathrm{C} 1}{ }^{\mathrm{V}} / \mathrm{DT}_{\mathrm{X}, \mathrm{C} 2}{ }^{\mathrm{V}}>1.1$ or $\mathrm{DT}_{\mathrm{X}, \mathrm{C} 1} \mathrm{~V}^{\mathrm{V}} / \mathrm{DT}_{\mathrm{X}, \mathrm{C} 2} \mathrm{~V}<1.04, \mathrm{RFI}_{7.3} \mathrm{~V}$ is present. The presence of both $\mathrm{RFI}_{7.3}$ and $\mathrm{RFI}_{6.9}$ of similar intensity leads to standard $\mathrm{DT}_{\mathrm{X}, \mathrm{C} 1} / \mathrm{DT}_{\mathrm{X}, \mathrm{C} 2}$ ratio and can be detected using the criteria on $\mathrm{DT}_{\mathrm{X}, \mathrm{C} 1}$, defined afford. The decision tree to outline the steps for $\mathrm{RFI}_{6.9}$ identification is shown in Fig. 2(b).

This type of RFI can also be visually identified by side by side analysis of $\mathrm{DT}_{\mathrm{C} 2, \mathrm{C} 1}$ and $\mathrm{DT}_{\mathrm{X}, \mathrm{C} 2}$. An increase in $\mathrm{DT}_{\mathrm{C} 2, \mathrm{C1}}{ }^{\mathrm{H}}$ in area 1 of Fig. 4(a), accompanied by the decrease in $\mathrm{DT}_{\mathrm{X}, \mathrm{C} 2}{ }^{\mathrm{H}}$ in Fig. 4(b), indicates the presence of $\mathrm{RFI}_{7.3}$. Contrarily to $\mathrm{RFI}_{7.3}$, rain over area 2 manifests itself as an increase in both $\mathrm{DT}_{\mathrm{C} 2, \mathrm{C} 1}{ }^{\mathrm{H}}$ and $\mathrm{DT}_{\mathrm{X}, \mathrm{C} 2}{ }^{\mathrm{H}}$. The last is featured by significantly larger amplitude. An increase in $\mathrm{DT}_{\mathrm{C} 2, \mathrm{C1}}{ }^{\mathrm{H}}$ in area 3, not accompanied by the corresponding increase in $\mathrm{DT}_{\mathrm{X}, \mathrm{C} 2}{ }^{\mathrm{H}}$ (inevitable if the reason had been rain), also signifies $\mathrm{RFI}_{7.3}$. The field of the ratio $\mathrm{DT}_{\mathrm{X}, \mathrm{C} 1}{ }^{\mathrm{H}} / \mathrm{DT}_{\mathrm{X}, \mathrm{C} 2}{ }^{\mathrm{H}}$ in Fig. 4(c) clearly shows these $\mathrm{RFI}_{7.3}$ as areas of either too large $(>1.4)$ or too small $(<1.07)$ values. Small $\mathrm{DT}_{\mathrm{X}, \mathrm{C} 1}{ }^{\mathrm{H}} / \mathrm{DT}_{\mathrm{X}, \mathrm{C} 2}{ }^{\mathrm{H}}$ values signify intense external signal at $\sim 7.3 \mathrm{GHz}$.

The threshold values for the ratio $\mathrm{DT}_{\mathrm{X}, \mathrm{C} 1}{ }^{\mathrm{H}} / \mathrm{DT}_{\mathrm{X}, \mathrm{C} 2}{ }^{\mathrm{H}}$, ensured by natural environmental variability, is much more seasonally and regionally independent than $\mathrm{DT}_{\mathrm{X}, \mathrm{C} 2}{ }^{\mathrm{H}}$. That is why the usage of the ratio of spectral differences is preferential as compared to the spectral difference $\mathrm{DT}_{\mathrm{X}, \mathrm{C} 2}{ }^{\mathrm{H}}$ itself analogously to $\mathrm{RFI}_{6.9}$ identification.

\section{RFI at $10.65 \mathrm{GHz}$}

As opposed to RFI at C-band channels, in most cases manifesting themselves directly in the fields of spectral differences, this type of RFI is very difficult to be identified. On the one hand the same approach could be applied as for Cband RFI detection, when a $T_{B}$ at higher frequency is used and the spectral difference correlations are analyzed. On the other hand great variety of atmospheric and oceanic states leads to great diversity in $T_{B}$ spectral differences if higher than $C$ - or $\mathrm{X}$-band measurements are considered. The establishment of the threshold values for $T_{B}$ differences or their ratios involving Ku-band channel measurements is possible but practically of no use.

An alternative global method for $\mathrm{RFI}_{10.65}$ identification can be used. This method is based on the analysis of the ratio $\mathrm{DT}_{\mathrm{X}, \mathrm{C} 1} / \mathrm{DT}_{\mathrm{C} 2, \mathrm{C} 1}$ or $\mathrm{DT}_{\mathrm{X}, \mathrm{C} 2}{ }^{\mathrm{H}} / \mathrm{DT}_{\mathrm{C} 2, \mathrm{C} 1}{ }^{\mathrm{H}}$ with respect the $\mathrm{T}_{\mathrm{B}}$ value at 6.9 or $7.3 \mathrm{GHz}$. An increase in $\mathrm{T}_{\mathrm{B}}$ at $10.65 \mathrm{GHz}$ due to atmospheric water or wind increase should be accompanied by the corresponding weaker increase in lower C-band frequency. This might be either 6.9 or $7.3 \mathrm{GHz}$. The correspondence of these two increases is defined by their relative values: $\mathrm{DT}_{\mathrm{X}, \mathrm{C} 1}{ }^{\mathrm{H}} / \mathrm{DT}_{\mathrm{C} 2, \mathrm{C} 1}{ }^{\mathrm{H}}$ or $\mathrm{DT}_{\mathrm{X}, \mathrm{C} 2}{ }^{\mathrm{H}} / \mathrm{DT}_{\mathrm{C} 2, \mathrm{C} 1}{ }^{\mathrm{H}}$. The normalization on the value of $T_{B}$ at C-band frequency is needed to get to more regionally and seasonally independent threshold value, removing SST dependence of the ratio.

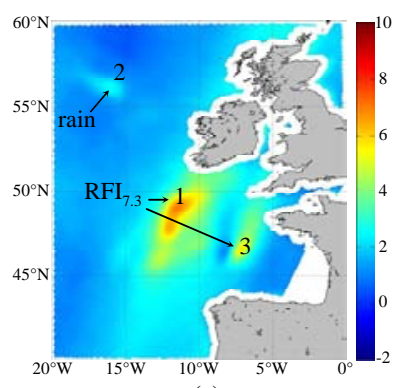

(a)

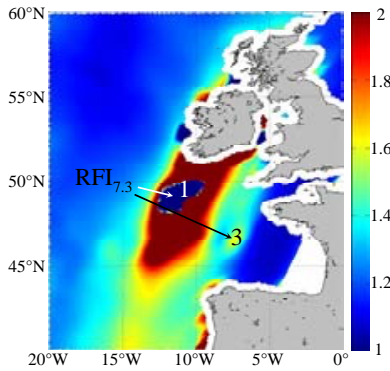

(c)

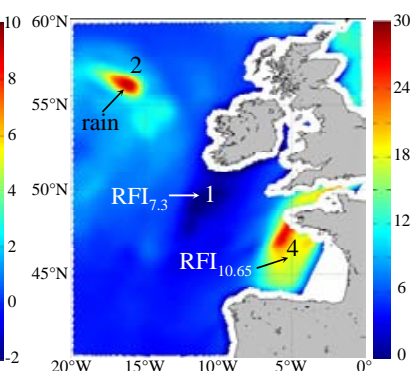

(b)

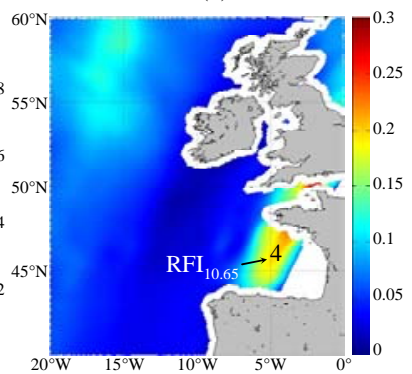

(d)
Fig. 4. AMSR2 measurement data on 3 September 2012 at 03:23 UTC: (a) $\mathrm{T}_{7.3}{ }^{\mathrm{H}}-\mathrm{T}_{6.9}{ }^{\mathrm{H}}(\mathrm{K})$; (b) $\mathrm{T}_{10.65}{ }^{\mathrm{H}}-\mathrm{T}_{7.3}{ }^{\mathrm{H}}$ (K); (c) $\mathrm{DT}_{\mathrm{X}, \mathrm{C} 1} / \mathrm{DT}_{\mathrm{C} 2, \mathrm{C} 1}$ (dimensionless unit); (d) $\mathrm{DT}_{\mathrm{X}, \mathrm{C} 2} / \mathrm{DT}_{\mathrm{C} 1, \mathrm{C} 2} / \mathrm{T}_{\mathrm{C} 2}\left(\mathrm{~K}^{-1}\right)$.

Model calculations and AMSR2 measurement data analysis show that in case there is no $\mathrm{RFI}_{10.65}, \mathrm{DT}_{\mathrm{X}, \mathrm{C} 1} / \mathrm{DT}_{\mathrm{C} 1, \mathrm{C} 2} / \mathrm{T}_{\mathrm{C} 1} \sim$ $0.03 \div 0.15 \mathrm{~K}^{-1}$ for both polarization states (Fig. 1, the lower plots). So, if $\mathrm{DT}_{\mathrm{X}, \mathrm{C} 1} / \mathrm{DT}_{\mathrm{C} 1, \mathrm{C} 2} / \mathrm{T}_{\mathrm{C} 1}>0.15 \mathrm{~K}^{-1} \mathrm{RFI}_{10.65}$ is present. In the presence of RFI at $6.9 \mathrm{GHz}$ only $\mathrm{RFI}_{10.65}$ of prevailing intensity can be detected by this method. In such a case the ratio $\mathrm{DT}_{\mathrm{X}, \mathrm{C} 2} / \mathrm{DT}_{\mathrm{C} 1, \mathrm{C} 2} / \mathrm{T}_{\mathrm{C} 2}$ can be used instead. If there is no $\mathrm{RFI}_{10.65}$ this ratio should be $\sim 0.03 \div 0.15 \mathrm{~K}^{-1}$. Too low values of the ratio mean simultaneous $\mathrm{RFI}_{6.95}$. If RFI in both $\mathrm{C}$ subbands is present the method might not work. The success in $\mathrm{RFI}_{10.65}$ identification in this case depends on the intensity of an artificial source of radiation. The steps for $\mathrm{RFI}_{10.65}$ identification are shown in Fig. 2(c).

An increase of $\mathrm{DT}_{\mathrm{X}, \mathrm{C} 1}$ in area 4 in Fig. 4 (b) is associated with $\mathrm{RFI}_{10.65}$. Yet, this increase cannot be interpreted as a $\mathrm{RFI}_{10.65}$ without calculation of $\mathrm{DT}_{\mathrm{X}, \mathrm{C} 2} / \mathrm{DT}_{\mathrm{C} 1, \mathrm{C} 2} / \mathrm{T}_{\mathrm{C} 2}$.

\section{CONCLUSION}

The general sources of the ocean RFI for AMSR2 measurements are television signals from geostationary satellites, reflected from the ocean surface and direct emission from surface-based sources. RFI covers the large and growing ocean areas and is now observed in new frequency bands. It affects greatly not only AMSR2 brightness temperatures but appears to be a growing cause of concern for satellite microwave radiometry in general. In order to properly detect RFI contamination, RFI identification methods for AMSR2 Cand X-band channels were developed. They use the threshold criteria on the discriminative functions of the spectral differences in $T_{B}$ values for two sub-bands of C-band and one $\mathrm{X}$-band taken at the same polarization state. These criteria were formulated on the basis of $T_{B}$ modeling complemented with the analysis of AMSR2 measurement data over oceans.

The suggested method is not fully developed. Only several 
combinations of RFI sources at AMSR2 C- and X-band frequencies are considered: $\mathrm{RFI}_{6.9}, \mathrm{RFI}_{7.3}, \mathrm{RFI}_{10.65}, \mathrm{RFI}_{6.9}+$ $\mathrm{RFI}_{7.3}$, and $\mathrm{RFI}_{6.9}+\mathrm{RFI}_{10.65}$. Moreover, the method will help to discriminate $\mathrm{RFI}_{7.3}$ or $\mathrm{RFI}_{10.65}$ signals from rain signals but won't work if both $\mathrm{RFI}_{7.3}$ (or $\mathrm{RFI}_{10.65}$ ) and rain are present. More analysis is needed to cover all possible combinations of rain and RFI at different frequencies. More insight into the regional variability of the threshold values for RFI identification is required.

Nevertheless the developed simple criteria can be used to detect most RFI contaminated pixels over the World Ocean for AMSR2 measurements in two C-sub-bands and X-band. Examples of the method performance are given the Auxiliary materials.

\section{REFERENCES}

[1] C. L. Gentemann, F. J. Wentz, M. Brewer, K. Hilburn, and D. Smith, "Passive microwave remote sensing of the ocean: An overview," in Oceanography from Space, Springer, 2010, pp. 13-33.

[2] W. J. Blackwell, I. Adams, A. Camps, and D. Kunkee, "Foreword to the Special Issue on Radio Frequency Interference: Identification, Mitigation, and Impact Assessment," IEEE Transactions on Geoscience and Remote Sensing, vol. 51, no. 10, pp. 4915-4917, 2013.

[3] D. R. DeBoer, S. Cruz-Pol, M. M. Davis, T. Gaier, P. Feldman, J. Judge, K. I. Kellermann, D. G. Long, L. Magnani, D. S. McKague, T. J. Pearson, A. E. E. Rogers, S. C. Reising, G. Taylor, A. R. Thompson, and L. van Zee, "Radio Frequencies: Policy and Management," IEEE Transactions on Geoscience and Remote Sensing, vol. 51, no. 10, pp. 4918-4927, 2013.

[4] G. Forte, J. Querol, A. Camps, and M. Vall-Llossera, "Real-Time RFI Detection and Mitigation System for Microwave Radiometers," IEEE Transactions on Geoscience and Remote Sensing, vol. 51, no. 10, pp. 4928-4935, 2013.

[5] M. Spencer, C. W. Chen, H. Ghaemi, S. F. Chan, and J. E. Belz, "RFI Characterization and Mitigation for the SMAP Radar," IEEE Transactions on Geoscience and Remote Sensing, vol. 51, no. 10, pp. 4973-4982, 2013.

[6] L. Li, P. W. Gaiser, M. H. Bettenhausen, and W. Johnston, "WindSat radio-frequency interference signature and its identification over land and ocean," IEEE Transactions on Geoscience and Remote Sensing, vol. 44, no. 3, pp. 530-539, 2006.

[7] E. G. Njoku, P. Ashcroft, T. K. Chan, and L. Li, "Global survey and statistics of radio-frequency interference in AMSR-E land observations," IEEE Transactions on Geoscience and Remote Sensing, vol. 43, no. 5, pp. 938-947, 2005.

[8] M. Aksoy and J. T. Johnson, "A Comparative Analysis of Low-Level Radio Frequency Interference in SMOS and Aquarius Microwave Radiometer Measurements," IEEE Transactions on Geoscience and Remote Sensing, vol. 51, no. 10, pp. 4983-4992, 2013.

[9] C. L. Gentemann, T. Meissner, and F. J. Wentz, "Accuracy of satellite sea surface temperatures at 7 and $11 \mathrm{GHz}$," IEEE Transactions on Geoscience and Remote Sensing, vol. 48, no. 3, pp. 1009-1018, 2010.

[10] K. Imaoka, T. Maeda, M. Kachi, M. Kasahara, N. Ito, and K. Nakagawa, "Status of AMSR2 instrument on GCOM-W1," presented at the Proc. SPIE 8528, Earth Observing Missions and Sensors: Development, Implementation, and Characterization II, 852815, 2012, vol. 8528, pp. $15-21$.

[11] E. Zabolotskikh, L. Mitnik, and B. Chapron, “An Updated Geophysical Model for AMSR-E and SSMIS Brightness Temperature Simulations over Oceans,” Remote Sensing, vol. 6, no. 3, pp. 2317-2342, 2014.

[12] E. V. Zabolotskikh, L. M. Mitnik, and B. Chapron, "New approach for severe marine weather study using satellite passive microwave sensing," Geophysical Research Letters, vol. 40, no. 13, pp. 3347-3350, 2013.

[13] N. Grody, J. Zhao, R. Ferraro, F. Weng, and R. Boers, "Determination of precipitable water and cloud liquid water over oceans from the NOAA 15 advanced microwave sounding unit," Journal of Geophysical Research: Atmospheres (1984-2012), vol. 106, no. D3, pp. 2943-2953, 2001.
[14] T. Meissner and F. J. Wentz, "The emissivity of the ocean surface between 6 and $90 \mathrm{GHz}$ over a large range of wind speeds and earth incidence angles," IEEE Transactions on Geoscience and Remote Sensing, vol. 50, no. 8, pp. 3004-3026, 2012.

[15] N. C. Grody, "Classification of snow cover and precipitation using the Special Sensor Microwave Imager,” Journal of Geophysical Research: Atmospheres (1984-2012), vol. 96, no. D4, pp. 7423-7435, 1991.

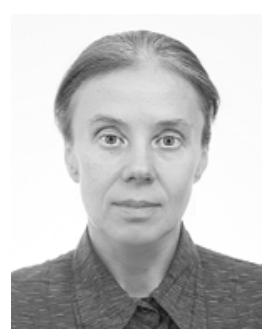

Elizaveta V. Zabolotskikh was born in Leningrad, Russia, in 1967. She received an Engineer Diploma in semiconductor physics from Leningrad Politechnical Institute named by Kalinin, Leningrad, Russia, in 1990, and the Ph.D. degree in physics and mathematics from St. Petersburg State University, St. Petersburg, Russia, in 2002.

From 1993 up to 1997 she worked as an engineer in the A.F. Ioffe Physical and Technical Institute, Russian Academy of Sciences. From 1997 to 2012 she worked at the Scientific Foundation "Nansen Environmental and Remote Sensing Centre”, St. Petersburg, as a senior scientist. She is currently a senior scientist at the Satellite Oceanography Laboratory, Russian State Hydrometeorological University, St. Petersburg. Her research interests cover satellite passive microwave measurement modeling, geophysical parameter retrievals and multi-sensor data analysis.

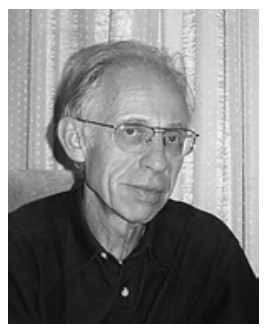

Leonid M. Mitnik (M’08) was born in Leningrad, Russia, in 1938. He received an Engineer Diploma in electrical engineering from Leningrad Electric Engineering Institute, Leningrad, USSR, Russia, in 1961, a Ph.D. in geophysics in 1970 from the State Hydrometeorological Center, Moscow, Russia, and a Doctor of Sciences degree in remote aerospace research in 1996 from the Institute for Space Research, Russian Academy of Sciences, Moscow, Russia.

He is presently a Head of the Satellite Oceanography Department, Pacific Oceanological Institute, Vladivostok, Russia. In 1965 he was employed by the Institute Radio Engineering and Electronics, Moscow. From 1974 to 1977 he worked as a senior scientist in the Leningrad Hydrometeorological Institute, Leningrad, Russia. In 1993-2004 he was a visiting Professor at several Universities in Taiwan, Germany, Japan and China. Since joining POI in 1977, he has worked in the area of passive microwave and radar remote sensing of the atmosphere-ocean system.

Prof. Mitnik's is a member of the Pan Ocean Remote Sensing Conference. His awards include: Goddard Space Flight Center Aqua Outstanding Teamwork Award, the National Aeronautics and Space Administration Aqua Group Achievement Award and PORSEC Distinguished Science Award.

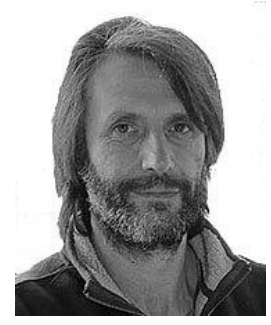

Bertrand Chapron was born in Paris, France, in 1962. He received the B. Eng. degree from the Institut National Polytechnique de Grenoble, Grenoble, France, in 1984 and the Doctorat National (Ph.D.) degree in fluid mechanics from the University of Aix-Marseille II, Marseille, France, in 1988.

He is presently the head of the Spatial Oceanography group at IFREMER, Plouzané, France. He is also responsible of the Centre ERS Archivage et Traitement. He is the co-investigator or principal investigator in several ESA, NASA and CNES projects. He is co-responsible of the ENVISAT ASAR-Wave Mode algorithms. He is a leading Scientist for the Satellite Oceanography Laboratory in the Russian State Hydrometeorological University, St. Petersburg, Russia. He has experience in physical oceanography, electromagnetic waves theory, and its application to ocean remote sensing. 